$\triangle 169$

LOW-DOSE INHALED NITRIC OXIDE (NO) IN INFANTS WITH BRONCHOPULMONARY DYSPLASIA (BPD).

Richard Mupanemunda and Michael Siverman. Department of Paediatrics and Neonatal Medicine, Royal Postgraduate Medical School, London, England.

BPD is characterised by severe maldistribution of ventilation, hypoxia, hypercapnia and pulmonary hypertension. Similar observations are made in adults with chronic obstructive lung disease (COLD), in whom impairment of endothelium-dependent pulmonary vascular relaxation has been demonstrated. Inhaled NO has recently been demonstrated to improve gas exchange in COLD. The effect of inhaled NO on gas exchange was therefore investigated in 6 infants (26-32 weeks gestation) with BPD receiving mechanical ventilation and with a fraction of inspired oxygen of $>0.7$. NO at doses of $5-40$ parts per million (ppm) was administered into the inspiratory gas for 15 minute periods with 10 minute washout periods. NO administration was continued at the lowest most effective dose when marked improvements in oxygenation were observed. Oxygen saturation $\left(\mathrm{Sa}_{2}\right)$, transcutaneous oxygen/carbon dioxide tensions (tc $\mathrm{pO}_{2} / \mathrm{tc} \mathrm{pCO}_{2}$ ) and systemic blood pressure (BP) were continuously monitored. Methaemoglobin (MetHB) and nitrogen dioxide $\left(\mathrm{NO}_{2}\right)$ levels were also measured. Inhalation of $\mathrm{NO}$ at all doses produced consistent improvements in the $\mathrm{Sa}_{2}$ and tc Inhalation of $\mathrm{NO}$ at all doses produced consistent improvements in the $\mathrm{Sa}_{2}$ and tc
$\mathrm{pO}_{2}$ (confirmed by concurent arterial blood gases). The tc $\mathrm{pCO}_{2}$ showed a tendency to $\mathrm{pO}_{2}$ (confirmed by concurrent arterial blood gases). The tc $\mathrm{pCO}_{2}$ showed a tendency to
fall. While $5 \mathrm{ppm}$ NO produced a smaller response in oxygenation parameters, $10-40$ ppm NO produced similar responses. The percentage changes from baseline values (median and range) in tc $\mathrm{pO}_{2}, \mathrm{IC}_{\mathrm{pCO}}$ and $\mathrm{Sa} \mathrm{O}_{2}$ at a dose of $10 \mathrm{ppm}$ were $+58.2 \%$ $(25-261.5),-15.8 \%(+2.6$ to -21$)$ and $+19.8 \%(5.5-52.5)$ respectively. NO was administered continuously for $9-52$ days with no evidence of tachyphylaxis. BP was marginally improved or unchanged. MetHB levels were $<2 \%$ and $\mathrm{NO}_{2}<1 \mathrm{ppm}$. We
conclude that inhaled $\mathrm{NO}$ improves gas exchange in BPD and speculate that NO synthesis and/or release max be_imoaired in BPD. (Supported by the Royal Society).

\section{$\triangle 170$}

CONJOINED TWINS - WHO LIVES? WHO DIES? WHO DECIDES? Jonathan K. Muraskas and Thomas F. Myers. Loyola University Stritch School of Medicine, Department of Pediatrics. Maywood, IL, USA. (Spon. by W. Patrick Zeller)

We recently cared for a set of thoracopagus conjoined twins that shared a complex 6 chamber heart and liver. This was the 10th reported case and attracted international attention on medical and ethical issues. No conjoined twin with a shared heart has survived longer than 3 months. Our infants were ventilator dependent since birth. The father was a substance abuser with a criminal record. After careful review and ethical consultation, we recommended extubation and humane care without surgical separation. Despite our pleas, the parents insisted on surgery. At 7 weeks of age, successful separation was accomplished with the sacrifice of one twin. At 7 months of age, she remains ventilator dependent with a medical bill exceeding 1.5 million dollars. Baby Doe regulations mandated treatment for the most seriously ill newborn. Is the U.S. health system geared to rescue rather than prevention? Do we continue to investigate the uninvestigated and try to achieve the unachievable? In a society which values individual freedom, do parents have the right to choose for their children regardless of costs and suffering? Can this surgery be considered an amputation? Is the sacrifice of one twin justifiable homicide? Faced with many unimmunized children as well as an expanding AIDS and aging population, could this money have been spent more wisely? In the emerging era of health care reform, who will have the ultimate decision to ration care? Exceptional cases as this will have to be scrutinized closely. The patient's welfare and physicians quest for knowledge must complement and not oppose each other

\section{$\Delta \mathbf{1 7 1}$}

MACROPHAGE INFILTRATION AND MATRIX DISRUPTION IN RDS.

Simon $\mathrm{H}$ Murch, Thomas $\mathrm{T}$ MacDonald and Kate $\mathrm{L}$ Costeloe.

Departments of Neonatal Medicine and Paediatric Gastroenterology, st Bartholomew's Hospital, London, UK.

We provide evidence for high-level macrophage infiltration early in the course of RDS by both sequential bronchoalveolar lavage (BAL) in 38 infants (13 BPD, 17 RDS and 8 controls) and immunohistochemical analysis of 45 post-mortem specimens.

Using lineage-specific markers we have shown that the majority of cells obtained by BAL after 48 hours are of macrophage origin, and most are immunoreactive for TNF $\alpha$. High level production of the macrophage-associated chemokine MIP-1 $\alpha$ and the cytokines TNF $\alpha$ and $I L-1$ were found from day 1 in RDS and BPD infants. The infants who developed BPD had significant elevation of inflammatory cell numbers and cytokine levels compared to those with an uncomplicated course. Dexamethasone significantly decreased all parameters within 24 hours.

Post-mortem specimens demonstrated interstitial infiltration of macrophages, polymorphs and TNF $\alpha+$ cells, maximal by 72 hours, associated with major disruption of sulphated glycosaminoglycans (GAGs), molecules of central importance in the control of albumin flux and tissue compliance (Lancet 1993; $341:$. $711-14$ ).

\section{$\Delta \mathbf{1 7 2}$}

CIRCULATING MEGAKARYOCYTE PRECURSORS IN NEONATAL THROMBOCYTOPENIA. Neil A. Murray, Irene AG. Roberts. Depts of Neonatal Medicine and Haematology, Royal Postgraduate

Neonatal thrombocytopenia (NT) occurs in $25 \%$ of newborns requiring intensive care. The mechanism of $N$ T is developed two assays to quantify circulating megakaryocyte precursors (MKp) - from the primitive megakaryocyte (MK) precursors (MKP) - from the primitive megakaryocyte (MK) specific antibody for cell identification. Cord blood ranges were established in healthy term $(T)$, and pre-term (PT) babies. PT babies had greater numbers of all MKp than I

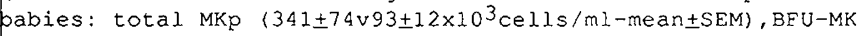
$(378 \pm 98 \mathrm{vl} 50 \pm 22 / \mathrm{ml}), \quad C F U-M K(3760 \pm 904 \mathrm{v} 874 \pm 105 / \mathrm{ml})$, mature MK $\left(33 \pm 8 v 8 \pm 1 \times 10^{3} \mathrm{cell} / \mathrm{s} / \mathrm{ml}\right)$. These numbers of MKp remained stable in the first week. However, PT babies who developed NT by $72 \mathrm{hrs}$ had reduced MKp at birth: total MKp $\left(60 \pm 5 \times 10^{3} \mathrm{cells} / \mathrm{ml}\right)$, BFU-MK $(32 \pm 10 / \mathrm{ml}), C F U-M K(463 \pm 119 / \mathrm{ml})$, mature $M K\left(5 \pm 1 \times 10^{3} \mathrm{cel} 1 \mathrm{~s}\right.$ $(\mathrm{ml})$. The MKp in PT babies with early NT rose in the first week, preceeding platelet recovery. In contrast PT babies who subsequently developed $\mathrm{NT}$ with infection/necrotizing enterocolitis, had normal to increased levels of circulating MKp. These data indicate that assaying circulating MKp is a
practical method of assessing neonatal platelet production, and provides a promising new way of investigating NT.

\section{$\Delta \mathbf{1 7 3}$}

MOTOR FUNCTION IN A VERY LOW BIRTHWEIGHT POPULATION AT EIGHT YEARS OF AGE - WILL THEY EVER CATCH UP? Lesley Mutch, Alastair Hall, Alice McLeod, Claire Counsell and Lesley Thomson, Public Health Research Unit, University of Glasgow, Glasgow G12 8RZ, Scotland. AIMS: To assess the motor functioning of a geographicaliy defined cohort of children born in Scotland with birthweights $<1500 \mathrm{~g}$ (VLBW) in comparison with two classroom peers of heavier birthweights. METHODS: 324 children $(96 \%)$ of the target population of 339 VLBW children still resident in Scotland, were assessed in school, along with two classmates of the same sex and age $(n=588)$. For those 24 children who were in special schools, no suitable comparison children were available. The Movement $A B C$ Test comprising tasks of gross motor function, manual dexterity, and balance and the Quick Neurological Screening Test (QNST) designed to detect children with a neurologica basis for their learning problems, were administered.

RESULTS: Having excluded the $23(7 \%)$ children with frank cerebral palsy (CP), $103(36 \%)$ of the VLBW Children performed below the loth centile of the comparison population on the Movement ABC Test. Of cent ile of the comparison population on the Movement ABC Test. Of
these, $72 \%$ had high or suspicious scores on the QNST; of the poorly these, $72 \%$ had high or suspicious scores on the QNST; of the poorly
performing control children (<10th centile) 52\% also had abnormal scores on the QNST. Overall $197(59 \%)$ of the VL.BW and $215(23 \%)$ of scores on the QNST. Overall $197(59 \%)$ of the VL.BW and 215 (23\%)
the compar. $.0 n$ children had CNST scores outside the normal range. CONCLUSICHS: At 8 years, VLBW children without CP still periorm poorly as a group, compared to the ir normal birthweight peers. Some of them $(28 \%)$ did not appear to have associated neurological problems. It is possible that this group of children could catch up with educational programmes designed to improve their fine and gross motor skills.

\section{$\triangle 174$}

A CONTROLLED POPULATION BASED STUDY OF THE COGNITIVE SKILLS AND EDUCATIONAL ATTAINMENT OF 8 YEAR OLD VERY LOW BIRTHWEIGHT CHILDREN IN SCOTLAND. Lesley Mutch, Alasta ir Ha 11, Cla ire Counsell, Alice McLeod and Lesley Thomson, Public

AIMS: To investigate the cognitive development of a 11339 very low birthweight (VLBW) children born and still resident in Scotland at the age of 8 years, in comparison to two classroom peers. We also the age of 8 years, in comparison to two classroom peers. We also
hypothesized that poor performance on the visual recognition subscale hypothesized that poor performance on the visual recognition

METHOD: Seven subscales of the 8ritish Ability Scales were used, testing short term visual and auditory memory, verbal reasoning, spatial imagery, visual reasoning, application of knowledge stored in long term memory and speed of information processing, from which an I0 was estimated. School attainment was assessed using the basic numbers skills and word reading scales.

RESULTS: For $24(7 \%)$ of the children receiving special education, no suitable comparison children were available. A $96 \%$ follow up rate was achieved. The VLBW children had significantly lower mean 10 scores than their controls (93.2, SE $0.77 \mathrm{vS} 101$.3, SE 0.51$)$; for the attainment tasks and for all of the cognitive subscales except short term auditory memory, the ir performance was significantly poorer. visual recognition scores at 4 tyears were not correlated with reading scores at 8 years.

CONCLUSIONS: Teaching techniques based on a phonetic approach may be more appropriate for those children not succeeding in acquiring reading skills by other methods based on short term visual memory. 